\title{
An evaluation of the Land and Environment Planning Toolkit for advancing soil and nutrient management on sheep and beef farms
}

\author{
K.A. SYNGE ${ }^{1}$, A.D. MACKAY ${ }^{2}$ and A.S. PALMER ${ }^{1}$ \\ ${ }^{1}$ Massey University, Private Bag 11222, Palmerston North \\ ${ }^{2}$ AgResearch Grasslands, Private Bag 11008, Palmerston North \\ alec.mackay@agresearch.co.nz
}

\begin{abstract}
The Land and Environment Planning (LEP) Toolkit recently re-launched by Beef + Lamb NZ is a package developed to assist the sector with resource and business planning. The toolkit includes workbooks and guidelines and consists of an introductory level (Level 1) through to more advanced Levels 2 and 3, each providing a stepby-step guide to assist farmers with on-farm business and environment planning. To date the evaluation of the toolkit has been very limited. Using a case study farm and interactive workshops, the usefulness of each of the three levels of the toolkit for tackling current and future drivers that will shape soil and nutrient management in hill country were determined. Each level was analysed against three drivers: freedom to operate, nutrient use efficiency and ability to demonstrate sustainability using a framework developed as part of the study. The findings from this research support the use of the LEP Toolkit in a stepwise approach. The introductory (1a and $1 \mathrm{~b}$ ) levels of the toolkit proved useful in raising awareness, but offered little assistance in developing tailored solutions. Level 2 and 3 proved more useful in advancing soil and nutrient management by breaking the farm down into land management units on the basis of the underlying physical resources. Level 3 with the inclusion of detailed resource information allows for a comprehensive analysis of the farm across all three drivers for both business planning and if required for reporting.
\end{abstract}

Keywords: Soil and nutrient management tools, sheep and beef, sustainability

\section{Introduction}

Environmental sustainability is of increasing importance to the worldwide agricultural sector (Parminter et al. 2004). For the sheep and beef sector there are a number of on-site (e.g. erosion, shade and shelter) and off-site (e.g. sediment and phosphorus (P) losses to waterways) challenges that need to be addressed as part of the long-term sustainability strategy for the sector. Land evaluation and planning, which includes assembling an inventory of the farm's physical resources, listing the strengths and limitations of the farm's land resources and developing an understanding of how the farm system and management decisions impact on these resources and the wider environment, provides a well proven methodology for assessing the current "status of the farm business". A comprehensive farm plan not only takes into account the immediate production opportunities and biophysical challenges, but must also consider the business in relationship to trends in the international market, along with cultural, social, regulatory and economic drivers (Parminter et al. 2004; Paterson \& Dewes 2011).

There are many soil and nutrient management tools currently available to the sheep and beef sector (e.g. Best Management Practices, OVERSEER ${ }^{\circledR}$ Nutrient Budget model, Nutrient Management Plans, Quality assurance plans, and the Beef + Lamb NZ Land and Environment Planning (LEP) Toolkit) that vary in their degree of sophistication, issues addressed, amount of input information required and as a consequence vary in the quality and comprehensiveness of the output generated. The ability of these tools to identify and address current soil and nutrient management challenges and the many complex and interrelated factors influencing their future management, including a future environment where there may be limits on emissions off-farm, is not well understood. The aim of this study was to gain insights into the contribution the Beef + Lamb NZ LEP Toolkit could make to advancing current and future soil and nutrient management challenges. The LEP Toolkit, recently re-launched by Beef + Lamb NZ, is a package developed to assist the sheep and beef sector with resource and business planning. The toolkit includes workbooks and guidelines and consists of an introductory (Level 1) through to more advanced Levels 2 and 3, each providing a step-bystep guide to assist farmers with on-farm business and environment planning.

\section{Research design}

In this study a multi-disciplinary approach was taken using both quantitative and qualitative methods and included a case study and interactive workshops, to determine the utility and value of each of the three levels of the Beef + Lamb NZ LEP Toolkit for advancing soil and nutrient management. The case study was on a commercial sheep and beef farm with 
both the farm manager and supervisor interviewed and the two interactive LEP Workshops were organised by Beef + Lamb NZ.

\section{Description of Case study farm}

Springvale Station (Rimanui Farms Ltd.) located on the Napier-Taihape road has a total area of 3201 ha (2900 ha effective). This consists of a mixture of topography ranging from river flats and upland plateaus to steep hillsides on greywacke and mudstone rock with the majority of the farm located on land classified as either strongly rolling $(49 \%)$ or moderately steep or steep hill country (24\%). The underlying geology of the area consists of a mixture of greywacke, sandstone, jointed mudstone and siltstone and some conglomerates found in the steep hill country. The rolling hill country is largely mantled with andesitic tephra deposits and the flats are a mixture of tephra deposits, gravels and alluvium. The soils formed under native forest that was cleared and put in to pasture approximately 100 years ago. The station runs a sheep and beef breeding and finishing operation. It produces approximately $8300 \mathrm{~kg}$ $\mathrm{DM} \mathrm{ha}^{-1} \mathrm{yr}^{-1}$ of pasture and is stocked at approximately 10.2 stock units (SU) ha-1. The main flock consists of Romney, while the breeding herd is predominantly Angus/Hereford crosses. The sheep: beef ratio is 59:41

\section{Stepwise evaluation of the LEP Toolkit}

For the case farm, Springvale Station, each level of the LEP Toolkit was completed according to the instructions (Beef + Lamb NZ 2012). Level 1 and 2 evaluations were conducted during the initial farm visit. The Level 3 evaluation was conducted later after the completion of the field work that included input of staff from both Landvision and Horizons Regional Council. The technical input and importance of developing a good working relationship between the professionals and land owner in the course of using the toolkit to develop a tailored plan is critical. As the analysis advanced through each level of the toolkit, the questions increased in complexity and depth, focusing more on specific environmental and production issues present on the farm.

\section{Description of Workshops}

The Beef + Lamb NZ workshops were held to introduce sheep and beef farmers within a district to the toolkit and to provide advice and guidance from both field experts and industry members (land managers, fertiliser representatives, and Beef + Lamb NZ representatives) about the application of the LEP Toolkit in resource management and business planning.

\section{Data collection and analysis}

Data were collected in two parts: through the case study farm and as part of the interactive LEP workshops. Primary data were collected during the fieldwork and interviews on the case farm, and during the LEP workshop meetings and immediately following through interviews. The fieldwork data and observations for all three levels of the LEP assessment were analysed according to the Boyatzis (1998) method for code development. Coding is the process of examining raw qualitative data in the form of words, sentences and experiences and assigning codes or labels to categorise the response. The coding strategy was used to assess the utility of the data collected at each level of the LEP against the three drivers influencing soil and nutrient management.

The drivers included:

Freedom to operate by meeting regulatory and industry requirements. For example, was the information collected as part of the process of completing a Level 1, 2 or 3 LEP sufficient to satisfy the consent requirements for a permitted activity? This was evaluated using a strict YES/NO code. Operational plans of two regional councils were used to as part of this process.

Nutrient use efficiency, i.e., to maximise returns from nutrient inputs and limit impacts on the environment. Again as part of the process of completing a Level 1, 2 or 3 LEP plan, the question was asked "What was the utility of the information collected for addressing nutrient management and related water quality challenges?" For example, for informing P fertiliser use and managing $\mathrm{P}$ losses to water, information collected as part of the process of completing each Level of the LEP Toolkit was given a rating of $0-6$, with $0=$ no knowledge gained, $3=$ understanding of the opportunity and issues, but limited quantitative information on which to act, $6=$ all the information required on which to act.

Ability to demonstrate sustainability. To test the LEP toolkit against this driver, the information collected as part of the process at each level of the LEP Toolkit was assessed against the requirements of an Environment Management System (Paterson \& Dewes 2011). Environmental management systems have been developed in part to assure customers that resources are not at risk of being depleted. Standard features of environmental management systems included the requirement to set performance targets, establish links between policy and environmental performance, monitor and record, self-audit and manage through review. A simple tick mark indicated if the standard feature listed in Table 1 was present or absent at each Level of the LEP Toolkit.

More details on the coding and background to each driver are provided in Synge (2013). The authors are very mindful of the subjective nature of the analysis and attempted to maintain autonomy throughout the process. 


\section{Results and Discussion}

The findings from both the case study farm and the interactive workshops were used to assess if the three levels of the LEP Toolkit progressively add the elements, flexibility and rigour necessary to address current and future soil and nutrient management challenges. At the start of each section a brief summary of the challenges facing sheep and beef farmers under each driver is provided before reporting on the utility of the Toolkit.

\section{Freedom to operate}

At present the regulatory requirements on land under sheep and beef farming operations are largely around vegetation clearance and tracking to reduce the risk of soil erosion and sediment loss. The Gisborne District Council has legislation in place to protect the most vulnerable of Land Use Class (LUC) Class 7 and all of LUC Class 8 land from accelerated erosion. Regulation to reduce non-point or diffuse nutrient losses from grazed pastures is currently limited to nitrogen $(\mathrm{N})$. An N-cap is in operation in the Taupo catchment (Environment Waikato 2008) and in priority catchments in the Manawatu Wanganui as part of the One Plan, $\mathrm{N}$ leaching limits are proposed (Horizons Regional Council 2012) to reduce non-point source losses of this nutrient. At least another four Regional Councils are currently in advanced stages of developing nutrient

Table 1. The number of features using a simple YES/NO technique: YES $(\checkmark)$ meets the criteria, NO (blank) does not meet the criteria of an Environmental Management System (EMS) addressed by Level 1, 2, 3 of the LEP Toolkit.

\begin{tabular}{lccc}
\hline EMS features & Level 1 & Level 2 & Level 3 \\
\hline Voluntary & $\checkmark$ & $\checkmark$ & $\checkmark$ \\
\hline On-going & & $\checkmark$ & $\checkmark$ \\
\hline Monitoring and recording & & & $\checkmark$ \\
\hline Self audited & $\checkmark$ & $\checkmark$ & $\checkmark$ \\
\hline Self managed & & & $\checkmark$ \\
\hline Links policy with & & & \\
environmental performance & & $\checkmark$ & $\checkmark$ \\
\hline Advocates continual & & & \\
improvement & & $\checkmark$ & $\checkmark$ \\
\hline Identifies risk (severity) & & $\checkmark$ \\
\hline Sets performance targets & $\checkmark$ & $\checkmark$ \\
\hline Lists actions & $\checkmark$ & $\checkmark$ \\
\hline Timeline for actions & $\checkmark$ & $\checkmark$ & $\checkmark$ \\
\hline $\begin{array}{l}\text { Progress check off } \\
\text { (implementation) }\end{array}$ & & $\checkmark$ \\
\hline Review & & $\checkmark$ \\
\hline Third party audit & & \\
\hline Certificate & & $\checkmark$ \\
\hline
\end{tabular}

limit policies. Regional concerns on other nutrients, and specifically $\mathrm{P}$ are largely governed and monitored by the activities around vegetation management and cultivation practices that can generate the loss of these nutrients e.g., cultivation, vegetation clearance on steep slopes (McDowell et al. 2004; Parfitt et al. 2008). While less of a concern to most sheep and beef producers, soil cadmium level is another issue that needs to be monitored as a potential future issue.

The introductory levels - Level $1 \mathrm{a}$ and $1 \mathrm{~b}$ of the LEP Toolkit - provide an insight into the potential issues on farm, such as the risk of soil erosion and the potential for sediment and $\mathrm{P}$ losses associated with cultivation and intensive grazing practices. It provides an insight into the potential size and severity of the issue to the farm business and prompts the user to develop a response. A Level 1 plan does not require the collection of resource information. This limits the use of the plan in, for example, a regulatory environment.

Level 2 requires a farm plan that breaks the farm down into land management units and records some of the underlying characteristics of each land unit. This assists in identifying how current land use and practices might create an opportunity or pose a possible threat to the environment. It also provides an indication of the size and extent of the soil and nutrient management opportunity or challenge and what it might mean to the existing farm business. It again encourages the development of an action plan and time lines to address each environmental challenge. While the additional features of the Level 2 plan starts to provide a focus to the specific actions required, again the limited resource information collected as part of the process is a constraint to the planning process.

Level 3 requires the development of a comprehensive whole farm plan. This is grounded in a farm scale land evaluation and includes a SWOT analysis of the physical resources, listing the opportunities and environmental challenges, including point and nonpoint sources contaminants and developing a detailed response plan. In the process of completing the land evaluation process all the underlying information required for calculating nutrient requirements and nutrient budgeting using OVERSEER ${ }^{\circledR}(6.0)$ are also collected. A Level 3 plan in place and operational, in addition to assisting in identify future opportunities, will also includes actions to protect that investment by ensuring continued freedom to operate.

\section{Nutrient use efficiency}

The growing interest in nutrient use efficiency is in part being driven by the industry looking for efficiency gains and in part as a possible option for reducing the environment footprint by reducing losses to the 
environment. Again interrogation of the introductory Levels ( $1 \mathrm{a}$ and $1 \mathrm{~b}$ ) of the toolkit proved useful in raising awareness of nutrient use efficiency, as part of both the case study farm and the workshop processes. Links between the nutrient issues, whether environmental or production focused, could not be advanced with the limited amount of information collected in the process of completing a Level 1 plan. For example, for informing $\mathrm{P}$ fertiliser use and managing $\mathrm{P}$ losses to water the information obtained as part of process of completing a Level 1 rated between 0-2, compared with 2-3 for Level 2 and 3-5 for Level 3. Unlike Level 1, Level 2 of the toolkit starts to identify production opportunities for more targeted fertiliser use and land suitable for forage crops and other intensive uses, as well as environmental challenges (erosion and critical source areas for $\mathrm{N}$ and $\mathrm{P}$ losses), with minimal outside input. Nutrient issues, particularly $\mathrm{N}$ and $\mathrm{P}$, are highlighted through the Level 1 and 2 evaluation process with a list of potential mitigation options for reducing losses and increasing the efficiency of use. However, even with a Level 2 plan in place it was not possible to interrogate in any substantive way options for increasing nutrient use efficiency or reducing the risk of nutrient losses on the case study farm.

All the requirements for a nutrient management plan were available in the Level 3 plan developed for the case study farm. This included a detailed nutrient budget and the land resource and production data required to develop a fertiliser programme to capture production opportunities and at the same time limit impacts on the environment.

\section{Ability to demonstrate sustainability}

The usefulness of the LEP Toolkit for demonstrating and tracking sustainable land use was tested against the environmental management system described by Paterson \& Dewes (2011). Standard features of their environmental management system included the requirement to set performance targets, establish links between policy and environmental performance, monitor and record, self-audit and manage through review, third party audit and certification. Few of the criteria set out by Paterson \& Dewes (2011) were meet by the Level 1a or 1b LEP developed for the case study farm (Table 1). While the Level 2 plan for the case study farm ticks more boxes (Table 1), it failed to address key features, including the setting of performance targets and monitoring and reporting, set out in the environmental management system. The Level 3 plan for the case farm ticked these boxes. The features it did not cover could be addressed if required, enabling Level 3 to be aligned with internationally accredited environmental management systems (Paterson \& Dewes 2011).

\section{Looking to the future}

The introductory level (1a and $1 \mathrm{~b}$ ) of the toolkit proved useful in raising awareness, but offered little assistance in developing tailored solutions. Level 2 proved more useful in advancing soil and nutrient management by breaking the farm down into land management units based on differences in the underlying physical resources. The process of breaking the farm down into units was useful in establishing the size and extent of the soil and nutrient management opportunity or challenge. Level 3 with the inclusion of detailed resource information allows for a comprehensive review of the farm across all three drivers for both business planning and, if required, for reporting. While not included as part of the evaluation in this study, an increased awareness and the ability to reduce-avoid-mitigate risk, for example from an adverse climatic event, are also all products of more comprehensive planning.

A recommendation from the research would be that greater use is made of Level 1 (1a and $1 \mathrm{~b}$ ) in raising awareness and in creating the case for sheep and beef producers once having completed Level 1 to advance to a Level 2 plan. Linking to other farm planning tools beyond OVERSEER ${ }^{\circledR}$ nutrient budget model to nutrient management plans, FARMAX, market orientated Quality Assurance plans and whole farm business plans (life cycle assessment) are critical steps in enabling the elements of the Level 2, and more so the Level 3 plans, to be incorporated into other aspects (e.g. business and market requirements) of the farming business. The greater integration of the LEP Toolkit with other farm planning tools becomes a driver for adoption of the package. Presently an integrated farm planning tool is under development that will have the ability to capture and integrate production information from multiple land management units for the analysis of the existing livestock policies and future investments on-farm (Rendel et al. 2013), increasing the value of the Level 2 and 3 plans to users.

\section{ACKNOWLEDGEMENTS}

To the manager and supervisor of Springvale Station (Rimanui Farms Ltd.) and all the staff that have being involved at the Horizons Regional Council and Landvision Ltd.

\section{REFERENCES}

Beef + Lamb NZ. 2012. Land and Environment Planning toolkit. http://www.beeflambnz.com/farm/ tools-resources/land-and-environment-planningtoolkit/ Retrieved 20 September 2013

Boyatzis, R.E. 1998. Transforming qualitative information: thematic analysis and code development. 
SAGE Publications Inc., Thousand Oaks, California. Environment Waikato. 2008. How land use affects Taupo. Accessed: February 2013. http://www. ew.govt.nz/Policy-and-plans/Protecting-LakeTaupo/\#Heading1 Regional Plan, Variation 5, Environment Waikato, Hamilton, NZ.

Horizons Regional Council. 2012. Environment Court Decisions. Accessed: September 2012. http://www. horizons.govt.nz/about-us/one-plan/appeals-tothe-proposed-one-plan-as-amended-by-decisionsaugust-2010/environment-court-decisions/

McDowell, R.W.; Biggs, B.J.F.; Sharpley, A.N.; Nguyen, L. 2004. Connecting phosphorus loss from agricultural landscapes to surface water quality. Chemistry and Ecology, 20: 1-40.

Parfitt, R.L.; Baisden, W.T.; Elliott, A.H. 2008. Phosphorus inputs and outputs for New Zealand in 2001 at national and regional scales. Journal of the Royal Society of New Zealand 38: 37-50.

Parminter, I.; Mackay, A.; Wharfe, L.; Frazer, A. 2004. Environmental management systems: A market driven tool for achieving clean green outcomes?
Primary Industry Management, 7: 9-12.

Paterson, J.; Dewes, A. 2011. The status of New Zealand agricultural sector owned environment management systems (EMS) - Are they a realistic alternative to averting further environmental regulation? In: Adding to the knowledge base for the nutrient manager. Eds. Currie, L.D.; Christensen, C.L. Occasional Report No. 24. Fertilizer and Lime Research Centre, Massey University, Palmerston North, New Zealand. http:// flrc.massey.ac.nz/publications.html. 10 pages.

Rendel, J.M., Mackay, A.D., Manderson, A. 2013. New generation integrated whole farm planning tool Proceedings of the New Zealand Grassland Association 75: 85-90.

Resource Management Act 1991.

Synge K. 2013. An evaluation of the Land and Environment Planning toolkit for advancing soil and nutrient management in hill country and steepland farm systems. Masters in Soil Science Thesis. Massey University, Manawatu, New Zealand.132 pp. 
